\title{
DIFICULTADES PROBATORIAS EN LA PERSECUCIÓN PENAL DEL DELITO DE MALTRATO ANIMAL: UNA REFLEXIÓN ACERCA DE LA PRUEBA DEL SUFRIMIENTO COMO RESULTADO TÍPICO
}

\author{
Proof Difficulties in the Criminal Prosecution of the Crime of Animal Abuse: \\ a Reflection on the Proof of Suffering as a Typical Result
}

\begin{abstract}
Carolina Leiva Labaca
Doctoranda en Derecho de la Universidad de Chile. Máster en Derecho Animal y Sociedad de la Universidad Autónoma de Barcelona. Fundadora de la bancada legislativa "Parlamentarios por la Dignidad Animal (PARDA) en Chile. E-mail: leivailabaca.carolina@gmail.com. OR-

CID:0000-0003-0102-7320
\end{abstract}

RESUMEN: El presente trabajo tiene por objeto plantear la problemática de la prueba del sufrimiento del animal en el proceso penal persecutorio de la comisión del delito de maltrato o crueldad animal, resultado elevado a elemento normativo típico dada la exigencia expresa de su concurrencia por parte del recientemente modificado tipo, en vigencia desde agosto de 2017 por disposición de la Ley 21.020 sobre tenencia responsable de mascotas y animales de compañía. Se exponen los problemas que se advierten como más evidentes y relevantes a la hora de determinar la concurrencia de un nuevo resultado típico que es se suyo de difícil comprobación empírica, dadas las propias características de la víctima y la gran diversidad de especies que concurren bajo el manto de protección penal de la norma. De la problemática expuesta, se ofrecen posibles soluciones probatorias a las que habría de arribar, indefectiblemente, a través del ejercicio de inferencias.

Palabras Clave: Delito de maltrato; Crueldad contra los animales; Código Penal de Chile; Inferencias probatorias; razonamientos abductivos.

Aвstract: The present work aims to raise the problem of proof of the suffering of the animal in the criminal prosecution of the commission of the crime of animal abuse or animal cruelty, a result elevated to a normative element given the express requirement of its concurrence by the recently modified type, in force since august 2017 by provision of the Law 21.020 on responsible ownership of pets and companion animals. The problems that are noticed as more evident and relevant when determining the concurrence of a new typical result that is difficult to prove empirically, given the victim's own characteristics and the great diversity of species that occur under the criminal protection mantle of the norm. From the problematic exposed, possible probatory solutions are offered to which it would arrive, unfailingly, through the exercise of inferences.

KeYwords: Crimes of abuse; Cruelty to animals; Penal Code of Chile; Probatory inferences; Abductive reasoning.

Sumário: 1. Introducción - 2. El tipo penal contenido en los artículos 291 bis y 291 ter del Código Penal, particular atención a la descripción provista por el 291 ter - 3. Dificultades probatorias aparejadas al tipo - 4. El problema: la prueba del sufrimiento del animal - 5. Los razonamientos abductivos como prueba del sufrimiento del animal - 6 . ¿Debe, el juez penal realizar un razona- 
miento probatorio distinto ante la concurrencia de este tipo penal? ¿Cuál sería el tipo de razonamiento más adecuado?; 7 . Conclusiones -8 . Notas de referencia.

\section{INTRODUCCIÓN}

Toda cuestión relativa a la prueba en el contexto de un proceso judicial o administrativo reviste indudables complejidades. Lo anterior se torna aún más complejo en materia penal, dada la mayor exigencia probatoria que reviste dicho proceso en consideración a la fuerza punitiva de las eventuales sanciones aparejadas en caso de arribarse a una sentencia condenatoria.

Teniendo como base las dificultades que reviste la prueba de los hechos en todo proceso penal, existe una situación que reviste aún mayores complejidades probatorias, cual es la de las dificultades probatorias en el contexto de la persecución penal del tipo contenido en los artículos 291 bis y ter del Código Penal de Chile: el delito de maltrato o crueldad animal.

En este tipo penal, de estructura indefectiblemente resultativa luego de las modificaciones introducidas al mismo por la Ley 21.020 de 2017 sobre tenencia responsable de mascotas y animales de compañía, nos encontramos con, a lo menos, los siguientes problemas particulares:

(a) la necesidad de probar los hechos constitutivos de la acción u omisión desplegada por el autor;

(b) la prueba de los hechos constitutivos del resultado exigidos por el tipo -los que no están, en la mayoría de los casos, "a simple vista"-;

(c) la prueba de la relación de causalidad entre la conducta desplegada y los resultados lesivos;

(d) la incardinación de dichos hechos-resultados dentro de lo que el tipo considera, dada la actual redacción del artículo 291 ter, como aquello que ha de entenderse por actos de maltrato o crueldad hacia animales (algo que, además, presupone una valoración de los hechos desde una perspectiva jurídico-normativa);

(e) la imposibilidad de obtener pruebas testimoniales de parte de las víctimas vivas;

(f) la enorme posibilidad de modalidades comisivas;

(g) el infinito abanico de hechos resultativos dada la también enorme diversidad de las víctimas protegidas (como son las diversas especies de animales presentes en la fauna, lo que difiere sustancialmente con los delitos contra las personas, en los que existe una relativa unidad de certeza científica respecto a los resultados de los atentados contra la vida, la salud y la integridad física);

(h) el problema que representa, atendido el recién referido, la falta de peritos que puedan dar cuenta de la causación de resultados para las diversas especies de animales; 
(i) la prueba de los hechos y la relación de causalidad en los casos de comisión por omisión del tipo, entre muchos otros.

Dentro de estas varias dificultades expuestas, existe una que constituye, a nuestro juicio, un problema probatorio insalvable. Se trata de la incorporación, en el tipo penal, del elemento normativo-resultativo (del) sufrimiento.

Dado todo lo anteriormente expuesto, el objetivo del presente trabajo será, por una parte, poner de manifiesto las dificultades generales que representa la prueba encaminada a determinar la concurrencia de este tipo penal, reseñando algunas de éstas, para luego enfocarnos en la particular situación de la prueba del elemento resultativo típico, a saber, la "causación de sufrimiento", e intentaremos identificar y proponer alguna posible salida epistemológica a esta problemática jurídico-probatoria mediante el análisis de algunas corrientes teóricas. Desde ya, se anticipa que se avizora que una posible solución al problema expuesto requerirá de la incorporación de razonamientos inferenciales, no estrictamente probatorios.

\section{El TiPO PENAL CONTENIdO EN LOS ARTíCUlOS 291 BIS Y 291 TER DEL Código PENAL, PARTICULAR ATENCIÓN A LA DESCRIPCIÓN PROVISTA POR EL 291 TER.}

En Chile, la modificación experimentada por el tipo penal el año 2017 incorpora el sufrimiento como uno de los resultados típicos de la conducta de acción u omisión desplegada por el agente, al señalar, en el nuevo Art. 291 ter. que

Para los efectos del artículo anterior se entenderá por acto de maltrato o crueldad con animales toda acción u omisión, ocasional o reiterada, que injustificadamente causare daño, dolor o sufrimiento al animal.

Sin duda, en algunos casos no revestirá mayores dificultades considerar como concurrente el sufrimiento cuando se encuentren también resultados lesivos de manera fácilmente identificables como "dañosos" o "dolorosos", pero será de suyo muy complejo cuando así ello no ocurriere.

Aunque una perogrullada, cabe señalar que es imposible preguntar al animal ¿sufriste?, y ¿cuánto?, como tampoco inferir su sufrimiento, o el alto o bajo nivel de éste, desde el propio sufrimiento humano.

Este tipo penal se encuentra contenido en los artículos 291 bis y 291 ter del Código Penal de Chile. Su existencia como tipo delictivo data del año 1989, año en que fue introducido en el código por la Ley 18.859, creadora del artículo 291 bis. En el año 2009, dicho precepto experimentó una escueta modificación en torno a un leve aumento en la penalidad asociada, esta vez por disposición de la Ley 20.380 sobre protección de los animales.

En agosto de 2017 la tipificación del delito de maltrato animal experimentó cambios relevantes: la Ley 21.020 incorporó dos nuevos incisos al artículo 291 bis y creó un nuevo artículo 291 ter, manteniendo intacto el núcleo típico en el inciso primero del 291 bis, de la 
forma que sigue:

Art. 291 bis. El que cometiere actos de maltrato o crueldad con animales será castigado con la pena de presidio menor en sus grados mínimo a medio y multa de dos a treinta unidades tributarias mensuales, o sólo con esta última.

Si como resultado de una acción u omisión se causare al animal daño, la pena será presidio menor en sus grados mínimo a medio y multa de diez a treinta unidades tributarias mensuales, además de la accesoria de inhabilidad absoluta perpetua para la tenencia de cualquier tipo de animales.

Si como resultado de las referidas acción u omisión se causaren lesiones que menoscaben gravemente la integridad física o provocaren la muerte del animal se impondrá la pena de presidio menor en su grado medio y multa de veinte a treinta unidades tributarias mensuales, además de la accesoria de inhabilidad absoluta perpetua para la tenencia de animales.

Art. 291 ter. Para los efectos del artículo anterior se entenderá por acto de maltrato o crueldad con animales toda acción u omisión, ocasional o reiterada, que injustificadamente causare daño, dolor o sufrimiento al animal.

De la sola lectura de la nueva tipificación, y particularmente de las incorporaciones adicionadas, se aprecia de manera clara que el tipo penal tiene a partir de éstas una estructura resultativa.

Así se advierte de la forma en que inician los dos nuevos incisos del 291 bis: "Si como resultado (...)", lo que se refrenda ya de manera concreta con la última parte del 291 ter: "que injustificadamente causare daño, dolor o sufrimiento al animal".

Como ya se adelantare se requerirá, por tanto y para la concurrencia del tipo penal en comento, de la causación de - a lo menos - alguno de los tres resultados típicos dispuestos por la norma, esto es, de daño, dolor o sufrimiento. Lo anterior a su vez implica la necesidad de probar la producción de, a lo menos, uno de dichos resultados lesivos.

En general, en los delitos de estructura resultativa no es menester probar la producción del resultado, sino que más bien la persecución penal se gatilla desde su mera constatación (como es el caso de las lesiones, en los delitos de lesiones, y la muerte, en el homicidio), por lo que los elementos a probar serán los hechos constitutivos de la conducta del autor y la relación de causalidad entre éstos y los resultados previamente constatados. Las leyes anti-crueldad son decretadas para imponer públicamente la visión ampliamente compartida de que el dolor injustificadamente infligido a un animal es inmoral.

El asunto no debería ser, necesariamente, distinto en el caso del tipo penal que sanciona el maltrato animal, empero, por las razones ya esbozadas y particularmente por el resultado causación de sufrimiento, el tipo penal impone la necesidad de probar también éste cuando su constatación no puede llevarse a cabo à première vue. 


\section{Dificultades probatorias aparejadas Al Tipo}

La prueba consiste en un conjunto de actos practicados por las partes, por terceros y por el juez para reconstruir la verdad y convencer a ese último, específicamente la conducta criminal, sus autores y las circunstancias objetivas y subjetivas del hecho.

La nueva redacción del tipo penal de maltrato o crueldad animal presenta, además de los requerimientos probatorios usuales de cada tipificación, una serie de particularidades que no dejan de dificultar la labor probatoria. Entre ellas distinguimos, grosso modo, las siguientes:

\section{A. Hechos a probar}

1) La conducta típica, entendida como la acción u omisión causadora del resultado desplegada por el agente.

2) Los resultados típicos, i.e., el daño, el dolor o el sufrimiento del animal.

3) La relación de causalidad que ha de existir entre la acción u omisión desplegada por el agente y los resultados.

4) La subsunción de los hechos-resultados dentro de lo que el tipo considera, dada la actual redacción del artículo 291 ter, como aquello que ha de entenderse por actos de maltrato o crueldad hacia animales (algo que presupone una valoración de los hechos desde una perspectiva jurídico-normativa).

5) La ausencia, o concurrencia, de la justificación del daño causado (ello más allá de las causales de justificación penal generales, ya que el tipo lo incorpora en la estructura resultativa de manera expresa).

B. Problemas probatorios

1) En lo relativo a los resultados típicos. Como se adelantare, en muchos casos la prueba del daño y el dolor no revestirá mayores complejidades, ya fuere por lo evidente del caso si el animal (vivo o muerto) presenta, por ejemplo, heridas atribuibles a la acción u omisión humana. El dolor, por su parte, puede revestir alguna mayor complejidad dada la diversidad de especies y sus consiguientes diferencias fisiológicas, pero ello puede salvarse de alguna manera con estudios empíricos existentes respecto a cada especie animal, además de la examinación de la víctima viva. El gran problema vendrá dado por la prueba del sufrimiento, y particularmente cuando se trate del sufrimiento síquico (ya que se entenderá sin más la concurrencia del sufrimiento cuando concurran los elementos resultativos daño o dolor).

2) En lo relativo a la prueba de la conducta omisiva, labor que resulta siempre dificultosa (la prueba de los "no-hechos").

3) La imposibilidad de obtener pruebas testimoniales de parte de las víctimas vivas.

4) El problema que representa la falta de peritos que puedan dar cuenta de la causación de resultados para la enorme diversidad de especies de animales. 
5) La prueba de los hechos y la relación de causalidad en los casos de comisión por omisión del tipo.

Claramente respecto a la prueba de varios de los elementos arriba expuestos las pruebas científicas serán las que alcancen una mayor relevancia en el proceso, particularmente las que puedan ser provistas por veterinarios, biólogos y etólogos. Ello no deja, por otra parte, de ser un asunto complejo, ya que coincidimos con la tesis exhibida por Gascón Abellán en su artículo "Prueba científica, un mapa de retos" en orden a la excesiva confianza que el sistema, principalmente el sistema penal, posa sobre este tipo de pruebas empíricas, a lo que la autora denomina una beatificación de este universo probatorio.

Gascón advierte, a nuestro juicio con bastante razón, que dicha confianza descansa en dos sobrevaloraciones: la sobrevaloración epistémica de la prueba científica (en cuanto a que sus resultados se aceptan como infalibles) y la sobrevaloración semántica de la misma (en cuanto a que se considera que esos resultados dicen cosas distintas de las que en realidad dicen).

De esta forma, aborda la invisibilidad generalizada que aqueja al sistema probatorio respecto de, por una parte, los posibles errores o desprolijidades tanto en el proceso científico mismo de la prueba como en la manera en que, con posterioridad, son expuestos y comunicados sus resultados.

En lo sucesivo nos enfocaremos de manera particular en uno de los problemas arriba planteados: el de la prueba del sufrimiento del animal cuando este configure, al menos aparentemente, el único resultado típico atribuible a la acción u omisión de agente.

\section{EL PROBLEMA: LA PRUEBA DEL SUFRIMIENTO DEL ANIMAL}

Según el diccionario de la Real Academia Española, sufrimiento significa 1) Padecimiento, dolor, pena, y 2) Paciencia, conformidad, tolerancia con que se sufre algo. Evidentemente, la primera acepción corresponde al elemento resultativo incorporado en el tipo penal.

El sufrimiento en humanos pareciera no revestir importantes problemas probatorios, ya que con un mero análisis intuitivo de carácter subjetivo nos es factible inferir el sufrimiento de otro a partir de las propias experiencias. No se requerirá jamás -sería muy extraño lo contrario- exigir la prueba del sufrimiento humano, al menos en materia penal (distinto a las situaciones fácticas ventiladas en sede civil a raíz, por ejemplo, de la prueba del daño moral).

Sin embargo, en el caso de los animales-no-humanos el sufrimiento sí representa un factor a probar y, además, uno muy difícil de probar. Como ya se señalare, muy probablemente se presentarán casos en que ello no revista mayores complejidades debido a que de una sola examinación visual, o una un tanto más profunda respecto a aspectos fisiológicos del animal, será posible advertir la presencia de sufrimiento (pensemos en los casos que han alcanzado alta connotación pública, como el caso de un perro quemado con agua hirviendo al exterior de un restorán o de un perro apaleado hasta la muerte al interior de una galería comercial). Quién podría aquí poner en duda el sufrimiento del animal. Distinto será, 
empero, en aquellos casos en que el sufrimiento no sea tan nítidamente evidenciado, como aquellos casos en que el sufrimiento sea derechamente emocional, por ejemplo.

Sin embargo, frecuentemente nos encontraremos con otros casos en que la presencia del sufrimiento no es tan evidente. Imaginemos situaciones tales como la mantención de animales confinados en jaulas en planteles productivos; la situación de animales de tiro o arrastre que trabajan durante horas bajo temperaturas muchas veces extremas cargando pesos que los superan en sus capacidades; animales que son abusados sexualmente de manera habitual; animales de compañía que aparentemente gozan de una buena salud física, pero que son maltratados síquicamente, ignorados o confinados en soledad y en espacios pequeños de manera constante por sus tenedores, o la no atención médica oportuna en el caso de la presencia de alguna patología.

Si se tratase del sufrimiento humano, el asunto sería bastante más simple: por una parte, tenemos la posibilidad de la inferencia a partir de nuestras propias experiencias de sufrimiento, lo que podría constituir, a lo menos, lo que Kant distingue como "un asenso subjetivamente suficiente, aunque sólo comparativamente si no conocemos otras condiciones bajos las cuales se pudiera alcanzar el fin", lo que estará configurado a partir de aquello que Russel identifica como "data", constituido por los asuntos de común conocimiento, de diversos tipos, entre los que distingue en primer lugar nuestro conocimiento respecto a varios objetos particulares en nuestra vida diaria (muebles, casas, pueblos, otras personas, etc.); en segundo lugar, la extensión de esos conocimientos particulares fuera de nuestra experiencia particular (a través de la historia y la geografía, los periódicos, etc.), y en tercer lugar, la sistematización de ese conocimiento de particularidades a través de las ciencias físicas. Por otra parte, siempre tendremos (en caso de víctimas vivas capaces de expresarse y comunicarse) la posibilidad de simplemente preguntarles, y con ello obtener una declaración en dicho sentido.

Sin embargo, con los animales no hay posibilidad de comunicación verbal que nos permita conocer a cabalidad si han experimentado, o están experimentando, sufrimiento, así como tampoco es posible determinar cuál es el nivel o el grado de ese sufrimiento.

Por tanto, no deja de ser un gran problema de razonamiento probatorio el de la determinación de la concurrencia, o no, de este resultado típico. Queremos pensar que el legislador aquí pretendió incorporar de alguna manera explícita la consideración por el bienestar síquico del animal, lo que parece a todas luces correcto y conteste con los avances científicos que dan cuenta de la amplísima vida emocional y síquica de los animales-no-humanos, la que puede de suyo verse afectada por la acción u omisión humana, lo que es conteste además con el reconocimiento a esta sensibilidad incorporado en la ley 20.380, que establece en su artículo $1^{\circ}$ inc. $1^{\circ}$ que :

Esta ley establece normas destinadas a conocer, proteger y respetar a los animales, como seres vivos y parte de la naturaleza, con el fin de darles un trato adecuado y evitarles sufrimientos innecesarios", agregando en su artículo $2^{\circ}$, in. $1^{\circ}$ que "El proceso educativo, en sus niveles básico y medio, deberá inculcar el sentido de respeto y protección a los animales, como seres vivientes y sensibles que forman parte de la naturaleza. 
Entonces, ¿cómo podemos probar la concurrencia del resultado sufrimiento en un animal no humano?, ¿cómo podemos tener ese sufrimiento por verdadero en el caso particular? Nos encontramos ante una situación que requerirá un ejercicio probatorio que distará bastante de los utilizados comúnmente para tener un resultado típico por verdadero en materia penal, y que muy probablemente revestirá características de algún tipo de razonamiento inferencial.

\section{Los RAZONAMIENTOS ABdUCTIVOS COMO PRUEBA DEL SUFRIMIENTO DEL ANIMAL}

El pragmatismo y el empirismo son dos corrientes filosóficas asentadas en la noción de experiencia, pero mientras el empirismo utiliza la lógica inductiva y toma la experiencia como experiencia pasada, el pragmatismo utiliza la lógica abductiva, y entiende la experiencia como apertura para el futuro, es decir, como la posibilidad de fundamentar la previsión, no en confrontación con la experiencia pasada, sino en relación con el posible uso futuro de esa experiencia pasada.

El ejemplo de la saca de frijoles dado por Peirce, permite una mayor comprensión:

1) Todos los frijoles de esa saca son blancos. Estos frijoles son de aquella saca. Por lo tanto, estos frijoles son blancos (deducción).

2) Estos frijoles son de aquella saca. Estos frijoles son blancos. Por lo tanto, todos los frijoles de esa saca son blancos (inducción).

3) Todos los frijoles de aquella saca son blancos. Estos frijoles son blancos. Por lo tanto, estos frijoles son de aquella saca (abducción).

La abducción comparte con la deducción el hecho de tener la regla general como premisa inicial (todos los frijoles....) y como la inducción ella arriesga una conjetura que puede resultar errada.

De los tipos posibles de inferencia, por lo tanto, la abducción constituye el único que se proyecta hacia el futuro, ya que tanto la deducción y la inducción dicen del pasado, del ya conocido, en la medida en que se refieren a la experiencia.

Contamos entonces con dos herramientas que componen nuestra data respecto al sufrimiento de un animal: en primer lugar, nuestro conocimiento común de aquello que entendemos por sufrimiento y el intento que subjetivamente realizaremos para comunicarlo (lo que no arroja una certeza probatoria alguna) al sufrimiento experimentado o experimentable por un animal-no-humano y, en segundo lugar, contaremos también con antecedentes científicos expuestos en la literatura especializada en general, los que darán habida cuenta de la posibilidad de experimentar sufrimiento por parte de un animal de una especie determinada, de qué razones pueden causar dicho sufrimiento y de cómo se expresa o manifiesta éste, tanto en los aspectos fisiológicos como conductuales del animal.

Así, por ejemplo, si desde las ciencias biológicas y etológicas se nos ha provisto de información empírica respecto a que los elefantes en vida libre (salvaje) son extremadamente sociales, viven en manadas matriarcales, que cuidan en conjunto a sus crías, que caminan decenas de kilómetros diarios y que, como contraparte, la imposibilidad de realizar estas conductas sociales les genera un enorme estrés y sufrimiento, lo que se explicita 
en la presentación de estereotipias (conductas reiterativas que realiza un animal y que no tienen ningún sentido $u$ objeto y que dan cuenta de la ausencia de bienestar) tales como el movimiento constante de su cabeza en ambas direcciones o el "zapateo" en la tierra con sus patas delanteras, pues tendremos claridad de que un animal particular, que pertenece a una especie determinada, en este caso un elefante, habría de desplegar tales conductas sociales y habría, en caso de verse imposibilitado de hacerlo, experimentar un sufrimiento consistente con el estrés que ello le causa.

Tenemos, entonces, una clara situación de necesidad de recurrir a una inferencia desde lo general a lo particular, en el sentido de: "los elefantes tienen tales y tales características sociales; éste es un elefante; este elefante tiene tales y tales características sociales", o "los elefantes manifiestan su sufrimiento de tal y tal manera; éste animal es un elefante; éste animal ha de manifestar su sufrimiento de tal y tal manera". Éste es el tipo de modo de inferencia típicamente conocido como deducción.

La deducción es un tipo clásico de razonamiento, al igual que la inducción:

Dado un enunciado $\mathrm{S}$ y un conjunto de enunciados K, se denomina deducción a una secuencia finita de enunciados cuyo último enunciado es $S$ (que es deducido) y tal que cualquier enunciado es o bien un axioma, o bien un enunciado de $\mathrm{K}$, o bien se sigue de enunciados anteriores en la serie mediante alguna regla de inferencia.

Suele caracterizarse, entonces, como un razonamiento deductivo aquella inferencia que va desde lo general a lo particular. Como contraparte, el razonamiento inductivo, o inducción es:

En un sentido estricto, la inferencia de una generalización a partir de sus instancias; 2) en un sentido más amplio, cualquier inferencia ampliativa -esto es, cualquier inferencia en la que la afirmación hecha en la conclusión va más allá de la que introducen las premisas conjuntamente.

Así, tenemos que la inducción, a diferencia de la deducción, es una inferencia que va desde lo particular a lo general. La abducción, por último, se presenta como "cánones de razonamiento para el descubrimiento, en oposición de la justificación, de hipótesis o teorías científicas.

Parece imposible lograr la prueba o la constatación de la concurrencia del elemento sufrimiento como resultativo en el tipo penal en comento a través de un razonamiento inductivo, ya que el ejercicio de subsunción penal pareciera ser, al menos para este caso, naturalmente deductivo. Nos centraremos, por tanto, en la deducción como razonamiento inferencial y veremos si, eventualmente, un ejercicio abductivo exhibe también alguna coherencia para el logro de tales fines.

Expuesta la idea de razonamiento deductivo, nos parece relevante reseñar ahora el modelo de la explicación nomológico-deductiva propuesto por Hempel en su obra "Filosofía de la ciencia natural" para comprender, de alguna manera, la forma en que actuaría un razonamiento deductivo aplicado en la resolución del problema en comento. 
Según Hempel, esta modelo tendrá por objeto, en base a la utilización de un razonamiento deductivo, la obtención de una explicación con la ayuda de leyes generales. Nos permitiremos utilizar aquí como leyes generales ciertos conocimientos científicos afianzados que dan cuenta de la estructura de comportamiento de una especie animal en determinados contextos, de la forma que sigue:

a) Los elefantes en vida libre son seres inherentemente sociales, viven en manadas y se trasladan más de 30 kilómetros diarios.

b) Los elefantes que, por su confinamiento, se ven imposibilitados de realizar estos comportamientos, sufren profundamente.

c) Los elefantes exteriorizan su sufrimiento a través de la realización de un determinado catálogo de estereotipias.

d) El elefante confinado que realiza estereotipias está sufriendo.

Con este ejemplo, creado en base al ejemplo del que se sirve Hempel para describir la explicación en base a las ideas de Torricelli y Pascal sobre la presión atmosférica, explicaremos la manera en que este modelo podría iluminar sobre la presencia o ausencia de sufrimiento en un animal en un caso determinado.

Siguiendo la argumentación de Hempel, podemos señalar que el fenómeno que se trata de explicar, presente en el enunciado d), es lo que cabría de esperar a la vista de los hechos explicativos a), b) y c), y de los que d) se seguiría deductivamente.

a), b) y c) son enunciados explicativos de dos tipos: a) y b) son leyes generales que expresan conexiones empíricas uniformes, mientras que c) describe ciertos hechos concretos. De esta forma, d) se explica mostrándolo como un hecho que tiene lugar de acuerdo a ciertas leyes de la naturaleza, como resultado de ciertas circunstancias concretas. Este tipo de explicaciones son conocidas como explicaciones por subsunción deductiva bajo leyes generales o como explicaciones nomológico-deductivas (nomos proviene de la alocución griega cuyo significado es "ley").

Tenemos, de esta forma, que el apoyo de leyes generales (las que en este caso indican la descripción del comportamiento de los elefantes por una parte, en vida libre y, por otra en cautiverio e imposibilitados de realizar los comportamientos que realizarían en vida libre), conjuntamente con la descripción de hechos concretos (como la presentación de estereotipias), no podemos esperar sino que d) se produzca, por lo que, a la luz y en presencia de a), b) y c), deducimos d).

Por otra parte y a continuación realizaremos un breve examen a efectos de determinar si la abducción, como razonamiento inferencial, pudiese servir para dar solución al problema propuesto.

La teoría de la abducción, propuesta por el filósofo estadounidense Charles Pierce, presenta un juego lógico de invertir los términos de un silogismo deductivo. Según esta inversión, la abducción puede entenderse como la inferencia de un caso a partir de una regla y un resultado. Aguayo identifica los siguientes rasgos definitorios en la teoría de la abducción: 
a) La abducción es una inferencia o un tipo de razonamiento. Su carácter inferencial se corresponde con la estructura lógica del razonamiento (silogismo) que acompaña al hecho de obtener un caso a partir de una regla y de un resultado. De esta forma, el caso resulta ser una creencia que es aceptada inferencialmente a partir de los conocimientos preestablecidos en las premisas (constituidas por la regla y el resultado).

Podríamos plantear el siguiente ejemplo:

Regla: Todos los elefantes libres se comportan de tal y tal manera

Resultado: Todos los elefantes en cautiverio, que no pueden comportarse de tal y tal manera, sufren.

Caso: Este elefante en cautiverio, sufre (Hipótesis).

b) La abducción es una inferencia mediata, por ser una inferencia mediada por otras dos proposiciones (la regla y el resultado).

c) La abducción es una inferencia mediata sintética, por cuanto ofrece como una conclusión del silogismo una ampliación del conocimiento expuesto en las premisas. Infiere de hechos de una clase, hechos de otra clase distinta.

d) La abducción es una inferencia mediata sintética probable, por cuanto se tiene por verdadera a partir de razones insuficientes que tienen, sin embargo, con respecto a las suficientes, una proporción mayor que las razones de lo contrario. De esto se sigue que no tendrá, necesariamente, la misma fuerza de la conclusión que derive de la deducción.

e) Su función en cuanto a inferencia es que la hipótesis que arroja explica el hecho observado, lo que es posible dado que la conclusión hipotética amplía el alcance de la semejanza entre los individuos.

De lo expuesto, parece altamente posible el utilizar también razonamientos abductivos cuando ello fuere necesario a la luz de la data de que se dispone. Por ejemplo, si nos encontrásemos ante el caso de una denuncia por maltrato animal en razón del confinamiento de un elefante, pero respecto del cual no se han obtenido evidencias de la presentación de estereotipias. En este caso, de la sola regla y resultado podría obtenerse una hipótesis que iluminará el proceso investigativo, ya que la abducción se presenta como el tipo de razonamiento que es capaz de formular hipótesis explicativas para hechos nuevos o sorprendentes.

6. ¿Debe, el juez penal realizar un razonamiento probatorio distinto ante la concurrencia de este tipo penal? ¿Cuál sería el tipo de razonamiento más adecuado? 
A continuación, expondremos un ejemplo. Se trata de un proceso penal por el delito de maltrato animal seguido en contra de un sujeto, a quien denominaremos S.A., quien fuera sorprendido en situación de flagrancia penetrando con su pene el ano de una perra comunitaria al interior de su domicilio.

Los testigos del hecho, vecinos del pasaje en que la perra habitaba y quienes cuidaban de ella y le proporcionaron alimento, redujeron a S.A. en el acto y llamaron a efectivos de Carabineros, quienes una vez en el lugar procedieron a detenerlo. Los cuidadores de la perra la llevaron a un centro veterinario a efectos de que fuera examinada de manera inmediata y, en caso de ser posible, extraer la mayor cantidad de pruebas biológicas posibles del cuerpo del animal.

El examen clínico realizado por el veterinario de turno arrojó efectivamente como resultado la penetración de la perra vía anal, con un objeto consistente con un pene humano. Además, pudieron rescatarse rastros seminales. Sin embargo, y ante lo evidentemente reprochable del acto, surgen aquí dos problemas: 1) El cuerpo de la perra no presentaba lesiones (como podría haberlas presentado el cuerpo otro animal de menor tamaño que hubiere sido penetrado de tal manera, como un perro más pequeño, una gallina o un conejo), y 2) la realización de actos sexuales con animales, el abuso sexual o derechamente la violación de un animal no se encuentran incorporados de manera expresa como conductas típicas en los artículos 291 bis y ter del Código Penal.

La conjunción de estos dos problemas nos lleva a, necesariamente, para subsumir el caso concreto al tipo penal (y evitando reducir el asunto a un reproche moral en contra de una conducta humana sexual desviada), a probar el sufrimiento síquico de la perra, esto es, la afectación que un acto en su contra, de tales características, genera en su vida mental.

Un ejercicio inferencial en el caso propuesto sería el siguiente:

Ejercicio de búsqueda de una explicación nomológico-deductiva

a) Los canes, en situación de bienestar síquico, exhiben tales y tales conductas y comportamientos.

b) Los canes que demostradamente han sido abusados sexualmente, experimentan alteraciones en su bienestar síquico, consistentes con el sufrimiento.

c) Los canes que demostradamente han sido abusados sexualmente, expresan su sufrimiento mediante la exhibición de tal y tal conducta.

d) El can que exhibe tal y tal conducta y del cual se conoce o se sospecha un abuso sexual, está sufriendo.

Ejercicio de inferencia abductiva (aplicable al caso, ya que no se contaba con antecedentes respecto a su posible afectación emocional):

Regla: Todos los perros en situación de bienestar síquico se comportan de tal y tal manera

Resultado: Todos los perros abusados sexualmente presentan tales y tales alteraciones en su bienestar síquico, consistentes en sufrimiento. 
Caso: La perra que fue abusada sexualmente presenta alteraciones en su bienestar síquico, por tanto, sufre (Hipótesis).

Según lo ya expuesto en orden a los tipos de razonamientos inferenciales presentados como unos posibles de ser utilizados en la determinación de la concurrencia del elemento típico resultativo sufrimiento, es menester ahora buscar cómo incorporar este tipo de razonamientos como prueba suficiente del sufrimiento en un proceso penal, esto es, cuando el razonamiento probatorio es la única prueba.

A este respecto García Amado, en su artículo "Elementos para el análisis de la prueba y del razonamiento probatorio en derecho" exhibe una distinción que nos parece ilumina el camino hacia esta cuestión: la distinción entre pruebas taxativas y pruebas no taxativas coadyuvantes. Las primeras son aquellas que proviene de un método científico o del saber tenido por indiscutible, de manera que se considera que no da lugar a error o que provoca resultados erróneos solamente en una muy baja proporción de casos. En tanto, las segundas serán aquellas que no aportan una razón definitiva o incuestionable para considerar algo por probado, pero sí ofrece una razón con algún peso no desdeñable para considerarlo por probado. Un ejemplo de las pruebas taxativas podrían ser los exámenes veterinarios practicados en la perra abusada sexualmente que dan cuenta de la efectiva ocurrencia de dichos hechos, en tanto, un ejemplo de las coadyuvantes podría ser la literatura científica que da cuenta de la causación de sufrimiento síquico en los perros producto del abuso sexual.

En este orden de cosas, requeriremos, por tanto, de algún tipo de razonamiento judicial que nos permita incorporar tantas pruebas taxativas como pruebas coadyuvantes en la ponderación, lo que sería consistente con la implementación de los tipos de razonamiento judicial propuestos por las teorías denominadas holistas.

Para la persecusión penal de los delitos ambientales, puede afirmarse que el uso de pruebas coadyuvantes solamente se legitiman cuando no es posible realizar un examen pericial directo debido a la desaparición de los vestigios materiales del delito cometido.

En cambio, para la persecución penal del delito de maltrato o crueldad, y particularmente en lo relativo a la prueba del elemento normativo sufrimiento, las pruebas coadyuvantes podrían representar la única forma de dar por establecida o, en otras palabras, tener por verdadera, su concurrencia.

Accatino, en su trabajo "Atomismo y Holismo en la justificación probatoria" expone las principales diferencias entre ambas corrientes y la manera que en una $\mathrm{u}$ otra son percibidas y recibidas por la comunidad jurídica. Señala que en este ámbito es común la discusión a favor y en contra de una u otra vertiente, como dos formas diferenciadas de razonamiento y valoración probatoria.

Nos parece que el holismo podría responder de mejor manera a la problemática planteada en este trabajo, por cuanto se trataría de "concepciones que afirman la similitud entre el razonamiento basado en relatos y el razonamiento abductivo, y que aplican a la prueba jurídica el modelo de la inferencia a la mejor explicación", lo que nos permitiría tener una mucho más amplia perspectiva de incorporación probatoria que una concepción atomista que, a contrario sensu, exigirá una atención rigurosa a las pruebas específicas disponibles como condición necesaria para que una decisión probatoria pueda considerarse justificada en el contexto del derecho. 
Para Accatino esto:

requiere un análisis individualizado de las inferencias inductivas que pueden construirse a partir de cada uno de los datos probatorios y de los contraargumentos críticos referidos a su fiabilidad, o bien al sustento empírico o la aplicabilidad al caso de la generalización en la que la inferencia probatoria se apoya.

Desde el favorecimiento de las teorías de corte holista, existen dos teorías expuestas por Accatino que nos parecen interesantes: 1) la teoría de la plausibilidad relativa y 2) la teoría fundaherentista de la justificación epistémica, de Susan Haack.

Como los criterios habrán de ser sopesados recíprocamente, sin una forma cerrada de combinación, la teoría de la plausibilidad relativa es aquella que caracteriza el proceso de decisión sobre la prueba como:

una evaluación de la plausibilidad relativa de las narraciones acerca de los hechos presentados por las partes, o construidos adicionalmente por los propios juzgadores, y, en sus formulaciones más recientes, asume que esta evaluación resulta representable como una inferencia a la mejor explicación o a una especie de razonamiento abductivo. La mayor o menor plausibilidad de un relato es una función de su consistencia, su simplicidad, su extensión (capacidad de explicar más y diferentes tipos de hechos) y su coherencia (concordancia con el background de conocimientos del juzgado.

Un elemento muy relevante en las teorías holísticas es precisamente el de la plausibilidad, cuyo posible valor justificativo resulta de la coherencia entre el relato y los conocimientos generales o de sentido común, cumpliendo un papel fundamental en la consideración de un relato determinado como probado. Ponen de relieve así la importancia del stock of knowledge del juzgador al momento de determinar la plausibilidad de un relato, independientemente de las pruebas que lo sustenten (es decir, con independencia y aún a falta de datos probatorios específicos sobre los asuntos ventilados en el proceso y que requieren de ser probados). Estos elementos son conocidos también como generalizaciones narrativas.

Ahora bien, y en ello coincidimos con Accatino, que este tipo de valoraciones de alto contenido psicológico podría derivar en decisiones probatorias epistemológicamente repudiables. Sin embargo, si estas generalizaciones narrativas se encuentran dotadas de sustento empírico, y no se trata de prejuicios infundados o de otro tipo de creencias erróneas, podría considerarse que este tipo de argumentos proporcionan algún nivel de justificación inductiva a las conclusiones arribadas, pasando así a tener una relevancia justificativa (independiente de que su grado de justificación epistémica sea, a la hora de la ponderación, relativamente bajo).

En segundo lugar, está la teoría fundherentista de la justificación epistémica, de Susan Haack. El modelo propuesto por la autora utiliza la imagen de un crucigrama a efectos de explicar cómo es que el grado de sustento epistémico de una narración depende de la calidad de las pruebas existentes a su respecto. De esta forma, la estructura de las pruebas, en el esquema de un crucigrama, no es lineal, sino ramificada, y lo que determinará que la calidad 
de unas pruebas sobre otras sea mejor o peor respecto de una afirmación será análogo a lo que hace que la respuesta a una entrada de un crucigrama sea más o menos razonable. Accatino favorece esta teoría en desmedro de la primeramente expuesta, por su consideración abarcadora del conjunto total de las razones probatorias y el relato global.

\section{CONCLusiones}

1) Si bien es posible afirmar que la labor probatoria no es un simple ejercicio matemático y que presentará siempre algún grado de complejidad, en el caso de la prueba en la persecución penal de los hechos constitutivos de maltrato o crueldad animal, aparecen mayores complejidades aún;

2) Que, de los razonamientos inferenciales clásicamente conocidos, se estima que la deducción y la abducción habrían de ser los que podrían responder a las preguntas respecto a cómo tener por verdadera la concurrencia del sufrimiento en un animal-no-humano en el contexto de un proceso penal.

3) Que, luego de ello, y ya derechamente dentro del ámbito de la ponderación judicial, pareciera ser imperativo que, para casos como este, dicha ponderación revista las características propias de las teorías holistas, ya que las atomistas dificultarían en extremo el uso y aplicación de razonamientos inferenciales para tener algo por verdadero.

4) Que, dentro de las teorías holistas, parecen adecuadas, al menos a modo ejemplar, las "de la plausibilidad relativa" y la "fundaherentista de la justificación epistémica", de Susan Haack, por cuanto permitirán, a través de la búsqueda de la coherencia entre el relato más probable y las pruebas disponibles, una ponderación que incluya elementos probatorios arrojados por razonamientos inferenciales.

5) Particularmente, el problema sobre la necesidad de probar la concurrencia del elemento típico resultativo "sufrimiento del animal" reviste complejidades de enormes proporciones, ya que, muchas veces, nos compele a recurrir a ejercicios probatorios distintos de los típicamente utilizados en materia penal, en especial a razonamientos inferenciales.

\section{NotAS DE REFERENCIA \\ (ENDNOTES)}

1. El delito de maltrato animal chileno no distingue entre especies o categorías de animales que entran dentro de su esfera de protección, sirviéndose solamente de la voz "animales" y "animal", en términos amplios.

2. KRELL, Andreas e LIMA, Marcos Vinício Cavalcante. A vedação constitucional de práticas cruéis contra animais e a correta interpretação das normas legais sobre vivissecção pelas comissões de ética no uso de animais. Revista Brasileira de Direito Animal v.10, n.19. 2015.p.133. Disponibele em: https:// portalseer. 
ufba.br/index.php/RBDA/article/view/14383/9897. Aceso em

3. CHILE. Ley 18.859, Artículo 291 bis.- "El que cometiere actos de maltrato o crueldad con animales, será castigado con la pena de presidio menor en su grado mínimo y multa de uno a diez ingresos mínimos mensuales, o sólo esta última". Antes de su entrada en vigencia, el maltrato animal era sancionado sólo como falta en el artículo $490 \mathrm{~N}^{\circ} 35$.

4. CHILE. Ley 20.380, disponible en https://www.leychile.cl/Navegar?idNorma=1006858\&buscar=20380

5. Sobre la historia del delito de maltrato animal en Chile, véase LEIVA ILABACA, C. (2018), El delito de maltrato animal en Chile: Historia del artículo 291 bis y análisis crítico a la luz del nuevo tipo penal incorporado por la ley $N^{\circ}$ 21.020, en GALLEGOS, J. y CHIBLE, M.J. (Eds) Derecho Animal, Teoría y Práctica. Santiago: Thompson Reuters.

6. CHILE. Ley 21.020, disponible en https://www.leychile.cl/Navegar?idNorma=1106037\&buscar=21.020

7. Artículos 291 bis y ter del Código Penal, modificado e introducido, respectivamente, por la Ley 21.020 de Tenencia responsable de Mascotas y Animales de Compañía.

8. Sobre la estructura evidentemente resultativa de la nueva tipificación penal, véase MAÑALICH RAFFO, J.P. (2017), Animalidad y Subjetividad, (borrador inédito).

9. CHIESA, Luis. Porque é um delito esmagar um peixinho dourado? - dano, vítima e a estrutura dos crimes de crueldade contra os animais. Revista Brasileira de Direito Animal v.8, n.13. 2013. Disponible en https:/ / portalseer.ufba.br/index.php/RBDA/article/view/8634/6176

10. SANTANA, Luciano Rocha e SANTOS, Clarissa P. G. dos. O crime maus-tratos aos animais: uma abordagem sobre a interpretação e a prova de materialidade e autoria (artigo 32). In: Crimes ambientais: comentários à lei 9.605/98. Ana Maria Moreira Marchesan e Annelise Monteiro Steigleder (organizadoras). Porto Alegre: Livraria do Advogado Editora. 2013, p.159

11. GASCÓN ABELLÁN, M. (2013) Prueba científica. Un mapa de retos. En VÁSQUEZ, C. (ed). Madrid: Marcial Pons

12. Diccionario on line de la Real Academia Española, disponible en http://dle.rae.es/srv/search?m=30\&w=sufrimiento

13. KANT, I. (2005) Crítica de la razón pura. Trad. RIVAS, P. Taurus.

14. RUSSEL, B. Our knowledge of the external world, as a field for scientific method in philosophy. Londres: George Allen \& Unwin Ltd.

15. CHILE. ley 20.380/13. Biblioteca del Congreso Nacional de Chile (BCN). Disponibile en: https:/ / nueva-justicia-animal-chile.webnode.cl/_files/200000006-da31adb289/ley_20380_3-10-09_protecc_animales. pdf

16. FÉLIX, Luciene. Charles Sanders Peirce. A lógica pragmática. Conhecimento sem fronteira. Escola Superior de Direito Constitucional. Disponible en http://www.esdc.com.br/CSF/artigo_2007_05_logica.htm

17. AUDI, R. (ed) (2004). Diccionario Akal de Filosofía. Título original The Cambridge Dictionary of Philosophy. Madrid: Akal. p. 235.

18. Ibidem, p. 535

19. Ibidem, p. 30

20. HEMPEL, C. Filosofía de la Ciencia Natural. Trad. DEANO, A. Madrid: Alianza Editorial. 1999. 
21. HEMPEL, C. Filosofía de la Ciencia Natural. Trad. DEANO, A. Madrid: Alianza Editorial. 1999, p. 79 y 80

22. En estos seguiremos lo expuesto por el Profesor Pablo Aguayo, en su trabajo "La teoría de la abducción de Pierce: lógica, metodología e instinto"...

23. AGUAYO, P. (2011). La teoría de la abducción de Peirce: lógica, metodología e instinto. Ideas y Valores. Vol. 60. núm 145. Bogotá: Revista Colombiana de Filosofía.

24. SOLER, T. y NEPOMUCENO, A. (2008) Deducción y abducción. Teorema, Vol. XXVII/1 pp. 5-16.

25. GARCÍA, J.A. (2014). Elementos para el análisis de la prueba y del razonamiento probatorio en derecho. GARCÍA. J.S. y BONORINO, P. (coords) en Prueba y razonamiento probatorio en derecho. Debates sobre abducción. Granada: Comares.

26. MINAHIM, Maria Auxiliadora; GORDILHO, Heron e PORTUGAL, Daniela. Los medios de prueba de los delitos ambientales cibernéticos. Cadernos de Dereito Actual No 8 Núm. Ordinario (2017), pp. 36 ISSN 2340-860X - ISSNe 2386-5229. Disponible em http://www.cadernosdedereitoactual.es/ojs/index.php/ cadernos/article/view/193.

27. ACCATINO, D. (2014) Atomismo y holismo en la justificación probatoria. Isonomia No. 40.

28. Ibid, p. 19

29. Ibid, p. 43

30. Ibid, p. 29

31. HAACK, S. (2013) "El probabilismo jurídico, una disensión epistemológica", en Vásquez, C. (ed) Estándaresde prueba y prueba científica. Madrid-Barcelona: Marcial Pons. 